\title{
El libro de mis primos de Cristina Peri Rossi. La fundación de un orden nuevo
}

\section{El libro de mis primos by Cristima Peri Rossi. The Creation of a New Order}

\author{
Pía Pasetti \\ Universidad Nacional del Mar del Plata, Mar del Plata, Argentina \\ Contacto: mpiapasetti@mdp.edu.ar \\ https://orcid.org/0000-0002-0064-7897
}

\section{RESUMEN}

El libro de mis primos (1969), novela de Cristina Peri Rossi (Montevideo, 1941), se construye alrededor de una familia regida por un sistema jerárquico, autoritario y violento que, hacia el final, es destruido por "los primos", esto es, los niños de la familia. Ellos son quienes tiran abajo la casa de sus antepasados, en un sentido tanto literal como simbólico. A la caída del orden familiar le sigue la caída de un Estado represivo, por lo que ambos órdenes colapsan de modo simultáneo. De esta forma, al mismo tiempo son demolidas dos instituciones definidas por la opresión y el autoritarismo. En este artículo nos interesa explorar los cruces entre ambas esferas, familiar y política, y para ello, estableceremos un diálogo con la situación política y social uruguaya - que será leída dentro del panorama revolucionario latinoamericano-, en el momento de publicación de la novela. Esto es, un momento de marcada agitación y efervescencia política, motivada, sobre todo, por el triunfo de la Revolución cubana, la emergencia de movimientos sociales locales y globales - condensados particularmente en 1968-, y la amenaza cercana de los golpes de Estado llevados a cabo en el Cono Sur, a lo largo de los años setenta.

Palabras clave: El libro de mis primos; Cristina Peri Rossi; Violencia revolucionaria

\section{ABSTRACT}

El libro de mis primos (1969), novel by Cristina Peri Rossi (Montevideo, 1941), is built around a family governed by a hierarchical, authoritarian and violent system which towards the end is destroyed by "the cousins", the children of the family. They are the ones who tear down the house of their ancestors, in a literal and symbolic sense. The fall of the family order is followed by the fall of a repressive state, so that both orders collapse simultaneously. In this way, at the same time, two oppressive and authoritarian institutions are demolished. In this article we are interested in exploring the intersections between both spheres, family and political, and for this, we will establish a dialogue with the Uruguayan political and social situation -which will be read within the Latin American revolutionary panorama-, at the time of publication of the novel. This is a moment of marked political agitation and effervescence, motivated, above all, by the triumph of the Cuban Revolution, the emergence of local and global social movements - particularly condensed in 1968-, and the near threat of the military dictatorships carried out in the Southern Cone, throughout the seventies.

Keywords: El libro de mis primos; Cristina Peri Rossi; Revolutionary Violence 


\section{Introducción}

El libro de mis primos (1969) de Cristina Peri Rossi (Montevideo, 1941), se construye alrededor de una familia regida por un sistema jerárquico, autoritario y violento, que hacia el final es destruida por "los primos", esto es, los niños de la familia. Ellos son quienes tiran abajo la casa de sus antepasados, en un sentido literal y simbólico. A la caída del orden familiar le sigue la caída de un Estado represivo, ambos órdenes colapsan simultáneamente. Así son destruidas dos instituciones opresivas y autoritarias. En este artículo nos interesa explorar los cruces entre ambas esferas, familiar y política; para ello, estableceremos un diálogo con la situación política y social uruguaya - que será leída dentro del panorama revolucionario latinoamericano-, en el contexto de publicación de la novela.

El texto fue publicado en 1969. En Uruguay existía un momento de agitación política, tensada entre el entusiasmo producido por el triunfo de la Revolución cubana y la emergencia de movimientos sociales locales y globales - condensados en 1968-, y la amenaza cercana de los golpes de Estado, ocurridos en el Cono Sur a lo largo de los años setenta (Saona, 2004). En ese contexto tienen lugar enfrentamientos cruentos entre el Movimiento Nacional Tupamaros - facción radicalizada de la izquierda uruguaya a favor de la lucha armada, surgida en 1965 - y las fuerzas militares, a cargo de "la lucha antisubversiva". Si bien en la novela no se alude de modo directo a ello, advertimos la presencia de ciertos elementos que, como lo demostraremos luego, remiten a la coyuntura social y política aludida.

\section{Escritura y compromiso}

Tres años después de la publicación de El libro de mis primos, ante la inminencia de un golpe de Estado, Cristina Peri Rossi tuvo que abandonar Montevideo para marcharse de modo clandestino a Barcelona, donde reside en la actualidad. Si bien la dictadura cívico-militar uruguaya comenzó un año después, en 1973, durante los años previos se desarrollaron las presidencias de Jorge Pacheco Areco (1967-1972) y Juan María Bordaberry (1972-1976), caracterizadas por censurar a medios de prensa y comunicación, prohibir partidos políticos de izquierda y ejercer una política autoritaria y represiva.
En la entrevista brindada en 1993 a la crítica española Parizad Tamara Dejbord, la autora profundiza sobre las circunstancias que generaron el abandono de Montevideo. Por un lado, se refiere a un hecho que motiva de modo definitivo su partida: el secuestro, por parte de los militares, de Ana Luisa Valdés, en 1972. Esta era una joven estudiante e integrante del MLN-T - Movimiento de Liberación Nacional-Tupamaros - a quien Peri Rossi alojaba, clandestinamente, en su domicilio. Por otro lado, señala la situación de peligro a la que estaba expuesta a causa de su participación en Marcha - "el semanario de la izquierda latinoamericana" (Dejbord, 1998, p. 220), según sus palabras - y por su militancia en el Frente Amplio, coalición de diversos partidos políticos de izquierda.

La figura de escritora que Peri Rossi construye durante aquellos años remite a la del intelectual comprometido, de raigambre sartreana, estrechamente vinculado con las problemáticas políticas y sociales del subcontinente. En sintonía con ello, la producción más temprana de la autora - que incluye El libro de mis primos - está sustentada por una concepción de la literatura como praxis social transformadora y con potencial revolucionario. En la novela analizada, esto se exhibe a partir de la puesta en marcha de diversas estrategias. Una de ellas es la referencia a producciones literarias de escritores latinoamericanos y españoles del siglo $\mathrm{XX}$, mayoritariamente poetas, quienes presentan como una zona de convergencia su vinculación con la izquierda política - con diversos matices - y el postular, en mayor o en menor medida, una idea de "literatura comprometida".

Nos referimos a la sección XI del libro, en la que se incluye la primera estrofa del poema de Rafael Alberti "A Rosa de Alberti, que tocaba, pensativa, el arpa" y un texto fragmentario, predominantemente lírico, compuesto por versos extraídos de libros leídos por Federico y Aurelia, dos personajes de la novela. En una nota al pie se explica que los versos intercalados por ellos, señalados en bastardilla, corresponden a los siguientes autores: Heberto Padilla, Ernesto Cardenal, Salvador Puig, Vicente Huidobro, Juan Gelman, Sarandy Cabrera, César Vallejo, Gonzalo Rojas, Pablo Neruda, Manuel Scorza y Jorge Arias. Vicente Huidobro y César Vallejo integraron el partido comunista 
chileno y español, respectivamente, y apoyaron la causa republicana de España, tanto en sus producciones como en diversas intervenciones en la esfera pública. El resto de los poetas mencionados en la nota presentan como un punto de religación su declarada adhesión a la Revolución cubana y remiten a la figura del "intelectual comprometido". El listado aglutina, en un mismo nivel, poetas canónicos junto con otros no tan célebres, provenientes, a su vez, de distintos países de América Latina: Cuba, Nicaragua, Uruguay, Chile, Argentina y Perú. El hecho de conglomerarlos en un único texto - nos referimos al elaborado por Federico y Aureliay reunir todos los nombres en una misma nota al pie provoca el efecto de una intelectualidad latinoamericana vinculada con la izquierda como un ente compacto, unido, sin fisuras, del que la misma autora, al incluir su voz, se presenta como integrante. Queremos insistir en el efecto de homogeneidad y la imagen de una intelectualidad latinoamericana de izquierda como un ente sin fisuras que se produce al aglutinarlos, subrayar su carácter artificioso, en tanto los autores citados han mantenido entre sí polémicas, distanciamientos y controversias. Pensamos, por ejemplo, en Heberto Padilla, o en las tensiones entre Pablo Neruda y Vicente Huidobro, o Pablo Neruda y Sarandy Cabrera, por mencionar solo algunos. del empleo de una primera persona plural inclusivacomo "hombres de transición". Esta idea atraviesa también el volumen El intelectual y la sociedad, publicado en 1969 — al igual que El libro de mis primos - en el que se reúnen los debates de Roque Dalton, René Depestre, Edmundo Desnoes, Ambrosio Fornet, Carlos María Gutiérrez y el propio Fernández Retamar en torno a la función del intelectual en el contexto de la Revolución cubana. En él, Carlos María Gutiérrez retoma y explica la idea de "hombres de transición" postulada en el poema de Fernández Retamar: aludiría a aquellos que parten de la sociedad burguesa y se encuentran a mitad de camino con el hecho de la revolución en el poder. En esa línea, se refiere a ellos mismos como intelectuales de transición entre la cultura burguesa que los formó y la cultura socialista que están ayudando a crear, se los presenta como los encargados de preparar "el parto de la nueva sociedad" que han soñado (Dalton et ál., 1969, p. 33).

$\mathrm{Al}$ respecto, Fernández Retamar, en su intervención en el volumen citado, plantea que la transición es de una conciencia individual a una conciencia colectiva (Dalton et ál., 1969, p. 28). Esta idea de "colectividad" asociada con la revolución se observa cuando en esa misma intervención establece un lazo, una co-

\section{El listado aglutina, en un mismo nivel, poetas canónicos junto con otros no tan céle- bres, provenientes, a su vez, de distintos países de América Latina: Cuba, Nicaragua, Uruguay, Chile, Argentina y Perú.}

Esta genealogía trazada también incluye, en la sección XV de la novela, las voces de dos figuras clave de la Revolución cubana: Ernesto "Che" Guevara, uno de sus principales ideólogos y ejecutores, y Roberto Fernández Retamar, cuya obra poética y ensayística aparece atravesada por dicha revolución. En relación con el Che, se cita un breve pasaje textual correspondiente a su diario: "yo bastante bien, pero con hambre atroz" (Peri Rossi, 1969, p. 149). El lugar de enunciación del guerrillero es el campo de batalla; se construye una imagen de líder que, más allá de las necesidades básicas insatisfechas - el alimento - continúa adelante con el objetivo revolucionario. Por otra parte, se intercalan dos fragmentos del poema "Usted tenía razón, Tallet: somos hombres de transición", de Fernández Retamar, en el que se define a sí mismo y a los intelectuales adheridos a la revolución - a partir rrespondencia con "los héroes de la Sierra Maestra" (Dalton et ál., 1969, p. 28), esto es, los guerrilleros encargados de la lucha armada: "asumimos los hechos de la Revolución, aunque no hayamos sido los sujetos individuales en ellos", y más adelante agrega: "nos enorgullecen, como cosa nuestra, Moneada, la Sierra - donde individualmente no estuvimos - Girón que para mí, personalmente, fueron varias noches sin dormir, de guardia, y un tiroteo... jen lo que hoy es la Plaza de la Revolución!-- la campaña de alfabetización, la crisis de octubre..." (Dalton et ál., 1969, p. 28). De este modo, aunque no haya estado en el campo de batalla, se siente y se sabe partícipe de la revolución. En tal sentido, advertimos que la yuxtaposición discursiva, en la novela de Peri Rossi, de las citas de Fernández Retamar y Ernesto Che Guevara remite a aquella idea del poeta y ensayista cubano: el brazo 
armado de la revolución y sus intelectuales componen un todo orgánico, religado por la esperanza de la nueva sociedad forjada por el socialismo.

\section{Destrucción creadora}

El libro de mis primos está construido alrededor de una familia oligárquica y patriarcal, regida por un sistema jerárquico, autoritario y violento, que finalmente es destruida por "los primos", esto es, los niños de la familia; particularmente, por uno de ellos, Oliverio. Este es el responsable de tirar abajo la casa de sus antepasados, en un sentido literal y simbólico: destruye la vivienda familiar - junto con sus objetos e incluso sus habitantes: tíos, tías y abuelos-, así como también sus tradiciones y valores. $\mathrm{Al}$ respecto, es menester señalar que la rivalidad entre el mundo infantil y el mundo adulto recorre la obra de Peri Rossi, y, en ese contexto, son los niños quienes - con diversas estrategias - buscan abolir el orden establecido encarnado por los mayores, concebido como arbitrario, injusto. Asimismo, la destrucción del orden familiar tiene su correlato con la destrucción de un Estado represivo, ambos colapsan de modo simultáneo, lo que se observa hacia el final del texto donde tienen lugar dos escenas yuxtapuestas: a la demolición de la vivienda familiar le sigue el ingreso de la guerrilla a la ciudad, con el fin de tomarla. Vale decir que entre los guerrilleros se encuentra Federico, "el primo mayor" de la familia. Como lo señala Margarita Saona (2004), en la novela, la familia y el estado represor constituyen concepciones de un antiguo orden que debe ser destruido para dar lugar a la utopía revolucionaria.

Oliverio, el niño, y Federico, el joven guerrillero, son, dentro del núcleo familiar, quienes se rebelan frente al orden establecido, en tanto pretenden derruir dos instituciones concebidas como opresivas y autoritarias, mediante la violencia. Federico acude a las armas. En cuanto a Oliverio, mientras juega con el resto de los niños a ser "soldados y guerrilleros" (Peri Rossi, 1969, p. 154), lanza una piedra, la cual va destruyendo todo lo que cruza a su paso, incluso a sus parientes mayores:

[...] me paré un poco más en la rama para ver bien la trayectoria de mi piedra, y vi justo cuando le daba en un ojo a mi tía Heráclita, que caía al suelo chillando, y el ojo caído rodaba por las escaleras como una bolita, saltaba de escalón en escalón mientras ella se revolcaba por el suelo, pero cuando Ernestina se acercaba corriendo, la piedra, al rebotar contra el marco de un cuadro, hizo un extraño giro y le dio en las entrañas a tía Ernestina, y yo me reí mucho desde el peral [...] la piedra cambiaba de dirección, doblaba, pasaba a otra habitación, donde el abuelo estaba inclinado comiendo choclos, entonces, suavemente, sin mucha furia, le daba un tic en las costillas y el abuelo caía al suelo, todavía masticando. (Peri Rossi, 1969, pp. 163-164)

Frente a los estragos causados, Oliverio se ríe. Él, junto con sus primos, comienzan "a gritar, de risa, de contento", mientras "el ruido de la casa deshaciéndose era infinito, una enorme ola, una tromba, el ruido de la casa eran vidrios rotos, muebles quebrados, paredes estriadas, cerámicas desmayadas, sangre sangre que corría" (Peri Rossi, 1969, p. 164). La algarabía parte de la creencia de estar clausurando un ciclo vetusto y refundando un nuevo tiempo. En este sentido, la pulsión destructiva remite a la idea de "violencia revolucionaria" desplegada por Agamben - a partir de las propuestas de Benjamin y Sorel- en "Sobre los límites de la violencia" (2016 [1970]), en tanto su objetivo es romper la continuidad, hacer saltar el continuum de la historia para iniciar una nueva época, un nuevo inicio del mundo.

Oliverio tiene el anhelo de "hacer una gran obra" (Peri Rossi, 1969, p. 29). Su sensibilidad y creatividad lo alejan del resto de la familia, fundada en un sistema patriarcal, representado por el padre y el abuelo, que el niño rechaza. Sin embargo, aquellos "grandes hombres", poderosos y temibles en el pasado, en la actualidad se muestran absolutamente impotentes. Una de las estrategias mediante las cuales se exhibe ello es la cosificación. En el apartado IX, el abuelo es cosificado a través de las estructuras comparativas, como la siguiente, en la que se establece un símil con un cristal: "Yo a veces me acerco a él [el abuelo] y lo toco un poco [...]; lo toco como a un cristal muy sensible que en cualquier momento se puede romper" (p. 85). Su rasgo distintivo es, ahora, la fragilidad. En esta sección, se advierte una tensión entre el pasado y el presente: mientras que Oliverio afirma no escucharlo hablar hace años, se aclara que, antes, "hablaba demasiado". 
Asimismo, su hija, madre de Oliverio, contrapone la quietud e indefensión actual del abuelo con su permanente actividad durante su juventud, exhibida, en el fragmento, en la saturación de verbos y verboides:

[...] ella podía recordarlo perfectamente dando órdenes, empujando a la gente, sometiéndolos a gritos, lo había visto obligando a los niños a comer del suelo la comida de los perros, lo había visto castigar a los peones, maltratar a los caballos, encerrar a sus hijas, lo había visto disparar contra los pájaros y destrozar los capullos, perseguir a las sirvientas detrás de las puertas y quemar la tierra de sus vecinos. (Peri Rossi, 1969, p. 83)

En el pasaje, asimismo, se pone de relieve su crueldad y violencia - condensada sobre todo en los infinitivos ("castigar", "maltratar", "encerrar", "disparar", "destrozar", "quemar")—, la cual es dirigida, en particular, a niños, empleados, animales, mujeres.

Esta tensión entre el pasado y la actualidad se advierte también, de manera exacerbada, en la descripción del padre de Oliverio quien, a diferencia del abuelo, muere, luego de una extensa agonía. En los recuerdos del niño, su padre, descripto como un "hombre alto, robusto, tan alto como un eucalipto" (Peri Rossi, 1969, p. 23), aparece asociado con un profundo terror: "no era solamente su altura la que me inspiraba el pánico [...], también su voz me producía estremecimientos desagradables" (p. 24). Junto con ello, es caracterizado como un déspota, desprovisto de sensibilidad. Ahora bien, en su agonía, dicha fortaleza y despotismo se desvanece: postrado en la cama, solo es capaz de abrir los ojos "amarillos y secos como las hojas viejas" (p. 20) y depende de la asistencia de otros para su cuidado. En el pasaje, el padre es cosificado hasta el punto en que los primos dedicados a su cuidado lo lanzan de uno a otro lado de la cama, juegan "a contarle los dientes que le quedan, las tiritas de piel que iba perdiendo, como escoriaciones sucesivas de un tronco de árbol” (p. 20). Así, se narra su progresivo estado de descomposición hasta la muerte.

El padre, muerto, y el abuelo, agonizante, exponen un paradigma de masculinidad que, en ese presente, se muestra obsoleto. Así como debe refundarse un orden nuevo, también debe postularse un hombre nuevo. En tal sentido, es menester mencionar "El so- cialismo y el hombre en Cuba", ensayo de Ernesto Che Guevara (2011), publicado en Marcha en 1965, en el que emplea esta expresión, "hombre nuevo", por primera vez, la cual, de acuerdo con Saona (2004), resulta esencial para la nueva izquierda latinoamericana.

El único hombre de la familia que, según la mirada de Oliverio - la voz narrativa que controla mayoritariamente la novela-, aparece provisto de cualidades positivas es Federico, quien, entendemos, remite a aquel "hombre nuevo" propuesto por el Che. Guerrillero y poeta, funciona como un modelo para el menor: "[...] a mí me gustaba asomarme al vano de su ventana y mirarlo [a Federico] escribir a máquina, apoyar los dedos salpicadamente en una u otra letra" (Peri Rossi, 1969, p. 128); "A veces él me dejaba entrar al cuarto y revisar sus cuadernos, su memorial, un libro que iba escribiendo con los sucesos de todos los días" (p. 129). Entre los aspectos valorados por Oliverio se destaca, además, el juego - "[Federico era] quien mejor jugaba conmigo" (p. 127)—; el amor por las plantas, a las que "tocaba con amor" (p. 160) —en contraposición con el abuelo, quien destrozaba los capullos-, y, sobre todo, el hecho de ser quien le enseña a escribir: "[me enseñaba] los colores de las letras, para que yo pudiera componer con ellas cuadros y poemas enteros" (p. 127).

Mientras que, para la mirada del niño, Federico representa múltiples virtudes, para el resto de la familia es un "paria", "un descastado" (Peri Rossi, 1969, p. 159), a quien "los libros le llenaron la cabeza de ideas raras" (p. 141). Así, su vinculación con la literatura, valorada y celebrada por Oliverio, para el resto de los integrantes familiares constituye una desviación, una mala influencia, en tanto contribuyó a la decisión de Federico de "irse a la guerrilla", lo que implica, para ellos, una vergüenza. Cabe decir que la cuestión de la guerrilla es presentada discursivamente de modo difuso, atravesada por lo no-dicho; frente a la pregunta de Oliverio, “AAdónde están las guerrillas?”, repetida como una letanía, solo se obtiene silencio.

La relación entre Federico y la literatura no solo es cuestionada por la familia, sino también por Alina, una compañera guerrillera, quien afirma necesitar para la lucha combatientes y no poetas. Federico, en lugar de aprovechar su tiempo y descansar - critica Alina-, pasa las noches debajo de los árboles, escri- 
biendo en su cuaderno: la escritura se presenta como una necesidad vital y urgente. En esa crítica realizada por la compañera de lucha surge el debate de la función de la poesía en la revolución: Alina no logra entender los poemas escritos por Federico, y critica que su poesía solo podría ser comprendida por una minoría, frente a lo que él responde: "Para eso mismo estamos haciendo la revolución. Para que todos tengan los medios para entender y apreciar [el arte]" (Peri Rossi, 1969, p. 152).

En esa respuesta resuena lo postulado por el Che en el ya mencionado ensayo "El socialismo y el hombre en Cuba", en el que plantea que no hay artistas de gran autoridad que, a su vez, tengan gran autoridad revolucionaria. Según Guevara, los hombres del Partido deben tomar esa tarea entre las manos y buscar el logro del objetivo principal: educar al pueblo. Critica que, en la esfera artística, se busque la simplificación, "lo que entiende todo el mundo", anulando así la auténtica investigación artística, y, finalmente, concluye que la culpabilidad de muchos de los intelectuales y artistas de izquierda reside en no ser auténticamente revolucionarios (Guevara, 2011 [1965], p. 17). Al respecto, coincidimos con Saona (2004) cuando plantea
En sintonía con ello, advertimos que la noción de revolución opera como un núcleo semiótico productor de sentido a lo largo de la novela. Por un lado, lo detectamos en los actos de Federico y Oliverio: mientras que el primero, poeta y guerrillero, es quien abandona la familia para tomar la ciudad, con el fin de instaurar un nuevo orden a partir de la revolución armada, Oliverio es quien, hacia el final, lanza la piedra que finalmente destruye la vivienda familiar, sus integrantes, su linaje. De este modo, Oliverio es portador del legado de Federico: ambos son capaces de demoler instituciones y sistemas considerados injustos, opresores; conjugan, al mismo tiempo, las cualidades de artistas y revolucionarios (Saona, 2004, p. 179). Por otro lado, lo observamos en la suerte de genealogía que Peri Rossi traza a través de las referencias a diversos escritores e intelectuales latinoamericanos de izquierda, adheridos a la revolución cubana, con el fin de exhibir dicha intelectualidad como un colectivo compacto y homogéneo. En tal sentido, caben mencionarse, además, las alusiones al brazo armado de dicha revolución, particularmente al Che Guevara. Intelectuales y guerrilleros, así, integran un mismo espacio.

\section{Junto con ello, reconocemos una figuración autoral signada por la noción de compromiso sar- treano, la cual nutre a gran parte de la intelectualidad latinoamericana durante la década del sesenta, que se siente, por primera vez, partícipe del destino del subconti nente (Verani, 1992).}

que la novela expresa un debate fundamental para la izquierda latinoamericana en aquellos años: el papel del arte en la revolución.

\section{Reflexiones finales}

En El libro de mis primos se postula una idea de escritura como praxis social transformadora, con un potencial revolucionario, que remite, también, a la propia práctica escritural de Cristina Peri Rossi durante el primer trayecto de su obra, en el que se incluye este texto. Junto con ello, reconocemos una figuración autoral signada por la noción de compromiso sartreano, la cual nutre a gran parte de la intelectualidad latinoamericana durante la década del sesenta, que se siente, por primera vez, partícipe del destino del subcontinente (Verani, 1992).
Publicado en 1969, El libro de mis primos condensa un clima de época, de efervescencia política, signado por la emergencia de movimientos sociales revolucionarios sumamente relevantes para la sociedad y cultura occidental. Como lo señala la misma autora en la entrevista con Parizad Dejbord ya aludida, "[a finales de los sesenta] todos estábamos comprometidos, al ser Montevideo una ciudad chica. Uno se sentía comprometido no sólo ideológicamente sino por amistad. Todos nos sentíamos implicados" (en Dejbord, 1998, p. 220). El entusiasmo producido por la fundación de un orden nuevo, un orden otro, y la certeza de que, efectivamente, aquel "parto de la nueva sociedad" (Fernández Retamar, en Dalton et ál., 1969, p. 33) está sucediendo, se cristaliza en la última línea de la novela, en la que un "nosotros" sentencia, en un grito: "HEMOS LLEGADO". 


\section{NOTAS}

11968 es el año del Mayo francés y de la Primavera de Praga. Junto con ello tiene lugar la guerra de Vietnam, la Revolución cultural china, y en América Latina se desarrolla el Movimiento de 1968 en México -cuya represión produjo, en octubre, la masacre de Tlatelolco-y, en Argentina, un año más tarde, el Cordobazo. Mabel Moraña (2004) se refiere a 1968 como "el año de condensación" de esa década, año de efervescencia y dislocación, de signos antagónicos y claroscuros; lo que en el Mayo francés implicó, siguiendo a la autora, "una fiesta de la imaginación y creatividad utópica", alcanzó en Tlatelolco uno de los momentos más siniestros de la historia de América Latina (2004, p. 126).

2 Bordaberry fue presidente constitucional entre 1972 y 1973, y a partir del golpe de Estado, dictador entre 1973 y 1976. Pacheco Areco, vicepresidente de Óscar Gestido, asumió la presidencia a partir de la muerte de aquel, en diciembre de 1967. Hacia el final de su mandato, Pacheco Areco terminó por configurar un discurso populista autoritario, centrado en su propia figura, construida en la confrontación con el enemigo subversivo, los Tupamaros, los cuales constituían el mal absoluto a ser expulsado de la patria (Basile, 2018, p. 85).

3 Valdés fue raptada en la puerta del domicilio de la autora y durante cuatro años estuvo en prisión, hasta que logró huir a Buenos Aires, y, posteriormente, a Suecia, donde realizó la carrera de antropología social en la Universidad de Estocolmo.

4 El Frente Amplio, fundado en 1971, se halla integrado por los partidos Comunista, Socialista, Demócrata Cristiano, más otros sectores menores de izquierda e independientes. Asimismo, restablecida la vida democrática luego de la dictadura, el MLN terminó incorporándose a este partido político.

5 El libro de mis primos obtiene, en 1969, el prestigioso premio "Biblioteca", otorgado por Marcha.

6 En el prólogo del poemario Estado de exilio (2003) se refiere a ciertas zonas comunes con Rafael Alberti: "Compartí con Alberti el hecho de ser exiliada, el amor al mar (que él llamó, siempre, la mar), la luz de Cádiz (tan similar a la de Montevideo) y el disgusto por la palabra rape (el pez, no el polvo de esnifar) (Peri Rossi, 2003, p. 11). Igualmente, dicho poemario obtuvo el Premio Internacional Rafael Alberti en su edición XVIII, a cien años de su nacimiento.

7 Mediante el nombre "Salvador Puig" se refiere al poeta y periodista uruguayo, crítico literario del semanario Marcha, cuyo nombre completo es "Salvador Bécquer Puig". Sin embargo, el nombre remite también a "Salvador Puig Antich", anarquista y antifascista español que formó parte del Movimiento lbérico de Liberación (MIL), y fue ejecutado en Barcelona por medio del garrote vil, en 1974.

8 El intelectual de izquierda de la década de los sesenta en América Latina fue una figura clave que rodeó las convulsiones políticas, en especial la Revolución cubana que era la atracción de los escritores "progresistas" del momento. La política se erige como su interés central, como la gran dadora de sentido (Basile, 2018, pp. 111-112).

9 En el título se establece un diálogo con Zacarías Tallet, poeta cubano, particularmente con su "Proclama", en el que en uno de los versos se enuncia: "Soy de la estirpe de los hombres puentes".

10 Posteriormente, en 1971, Fernández Retamar publica el célebre ensayo Calibán. Como bien lo señala Teresa Basile, este cifra en gran medida uno de los proyectos intelectuales emblemáticos de los años sesenta en América Latina "en tanto traduce las demandas ideológicas e intelectuales de la revolución cubana: en la defensa de los valores libertarios y revolucionarios, en la recuperación de zonas de la historia latinoamericanas opacadas por la historia oficial, y en la elección, como signo de la identidad latinoamericana, de la figura del mestizo y colonizado que Rodó ignoró en su ensayo Ariel (1900)" (2018, p. 108).

11 La tensión entre niños y adultos se desarrolla, en especial, en los libros de cuentos La tarde del dinosaurio (1976) y La rebelión de los niños (1980).

12 Federico remite a la figura de "intelectual armado". En el estudio El desarme de Calibán (2018), Teresa Basile atribuye a Ernesto Che Guevara -como así también a Fidel Castro, Raúl Sendic y otros líderes de los movimientos guerrilleros- el concepto de "intelectual armado"; stricto sensu, esto es, intelectuales que vincu- 
lan los argumentos de las armas en sus textos al empleo de las armas. Asimismo, la noción, en un sentido más amplio, abarca también al cordón de intelectuales que, sin una participación militar, rodea o es simpatizante del grupo revolucionario, y fundamenta la opción por la revolución armada, dando cuenta de ella a través de la literatura, del arte, del ensayo de ideas (p. 112). El concepto de "intelectual armado", como lo explica la autora, es recuperado de Herbert Gatto (2004), quien lo elabora para el campo intelectual uruguayo en torno al MLN-Tupamaros.

13 Este debate se exhibe en la célebre polémica entre Julio Cortázar y Óscar Collazos, clave para la cultura y literatura de América Latina, surgida en 1969 en Marcha.

14 Mayúsculas en el original.

\section{Referencias bibliográficas}

Agamben, G. (2016 [1970]). Sobre los límites de la violencia. Fractal. Revista de teoría y cultura, 78. México. https://www.mxfractal.org/articulos/RevistaFractal78Agamben.php

Basile, T. (2018). El desarme de Calibán. Debates culturales y diseños literarios en la posdictadura uruguaya. Pittsburgh: Instituto Internacional de Literatura lberoamericana.

Dalton, R., Depestre, R., Desnoes, E., et ál. (1969). El intelectual y la sociedad. Ciudad de México: Siglo Veintiuno Editores.

Dejbord, P. (1998). "Entrevista a Cristina Peri Rossi". En Cristina Peri Rossi: escritora del exilio. Buenos Aires: Galerna.

Fernández Retamar, R. (1984). Calibán. Apuntes sobre la cultura de nuestra América. Buenos Aires: Editorial La Pleyade.

Gatto Fernández, H. (2004). El cielo por asalto. Montevideo: Taurus.

Guevara, E. (2011 [1965]). El socialismo y el hombre en Cuba. La Habana: Ocean Sur.

Moraña, M. (2004). Crítica impura: estudios de literatura y cultura latinoamericanos. Madrid, Fráncfort del Meno: Iberoamericana, Vervuert.

Peri Rossi, C. (1969). El libro de mis primos. Montevideo: Biblioteca de Marcha.

Peri Rossi, C. (1976). La tarde del dinosaurio. Barcelona: Planeta.

Peri Rossi, C. (1980). La rebelión de los niños. Caracas: Monte Ávila.

Peri Rossi, C. (2003). Estado de exilio. Madrid: Visor Libros.

Saona, M. (2004). La familia del "hombre nuevo" y la revolución en El libro de mis primos de Cristina Peri Rossi. En M. Saona, Novelas familiares. Figuraciones de la nación en la novela latinoamericana contemporánea. Rosario: Beatriz Viterbo.

Verani, H. (1992). Narrativa uruguaya contemporánea: periodización y cambio literario. Revista iberoamericana, 58(160-161), 777-805. https://doi.org/10.5195/REVIBEROAMER.1992.5074 